\title{
Maternal recognition of pregnancy signal or endocrine disruptor: The two faces of oestrogen during establishment of pregnancy in the pig
}

\author{
R.D. Geisert ${ }^{1}$, J.W. Ross', M.D. Ashworth', F.J. White', G.A. Johnson'² \\ and U. DeSilva' \\ 'Department of Animal Science, Oklahoma Agricultural Experiment Station, Oklahoma State \\ University, Stillwater, OK 74078 and '2Department of Veterinary Integrative Biosciences, Texas A\&M \\ University, College Station, TX 77843, USA
}

\begin{abstract}
Timing of conceptus growth and attachment to the uterine luminal epithelium is regulated by progesterone secretion from the corpus luteum and by expression of progesterone receptor in the uterine epithelia and stroma. Conceptus growth and uterine attachment are temporally associated with the disappearance of progesterone receptors from uterine epithelia. While the loss of progesterone receptor from the endometrial epithelia on day 10 of the oestrous cycle and pregnancy has been well documented, the factors involved with cell specific down-regulation of progesterone receptor are yet to be established. We propose that several progesterone stimulated factors activate nuclear factor kappa B (NF-kB) within the uterine epithelia, which leads to inhibition of progesterone receptor and concomitant stimulation of endometrial genes expressed during early conceptus development. Although oestrogens secreted by pig conceptuses function to establish pregnancy, timing of endometrial exposure to oestrogen is critical. Early oestrogen administration alters the pattern of gene expression through the NF-kB system desynchronising the uterine environment for conceptus implantation resulting in later embryonic loss.
\end{abstract}

\section{Introduction}

The fundamental mechanisms for the regulation of the oestrous cycle and establishment of pregnancy in the pig are well established. For years we have known that following ovulation of the ovarian Graafian follicles during oestrus, synthesis and release of progesterone from developing corpora lutea $(\mathrm{CL})$ is the principal driver of endometrial secretion and receptivity for early conceptus development and implantation (see review Geisert and Yelich, 1997). In the absence of conceptuses, progesterone stimulates synthesis and pulsatile release of endometrial derived prostaglandin $\mathrm{F}_{2 \alpha}\left(\mathrm{PGF}_{2 \alpha}\right)$ into the uterine vasculature after day 12 of the oestrous cycle to induce $C L$ regression on days 15-16 and a return to oestrus between days 18-21 in the sow. During pregnancy, $\mathrm{CL}$ are maintained in the sow following rapid elongation of the developing conceptuses throughout the uterine horns on day 12 (Geisert et al. 1982). Conceptus 
secretion of the "maternal recognition of pregnancy signal", oestrogen, redirects endometrial $\mathrm{PGF}_{2 \alpha}$ secretion into the uterine lumen where it is sequestered and metabolised to prevent luteolysis (see review Bazer et al., 1982).

In the pig endometrium, a clear spatiotemporal association exists between the redirection of $\mathrm{PGF}_{2 \alpha}$ release, decline in progesterone receptor (PR) from the luminal (LE) and glandular (GE) epithelium, and receptivity for conceptus implantation. Down-regulation of PR in endometrial epithelia is a conserved event among mammals that is associated with opening of the implantation window in the mouse (Tan et al., 1999), pig (Geisert et al., 1994), sheep (Spencer and Bazer, 1995), and human (Lessey et al., 1988). Although down-regulation of PR within LE and GE has been well documented, cellular and molecular mechanisms responsible for specific loss of PR from uterine epithelia are relatively unknown. Unlocking the pathway controlling uterine epithelial PR expression would provide a significant insight into the mechanisms regulating the oestrous cycle and implantation in the pig. Possible clues to the compartmental regulation of endometrial PR down-regulation have begun to emerge with recent reports of a mutual negative interaction between the transcription factor, nuclear factor kappa $B(N F-\kappa B)$ and $P R$ (Kalkhoven et al., 1996; MCKay and Cidlowski, 1998). Loss of PR in the endometrial epithelia is correlated with increased activation of components of the NF-kB signalling pathway (Kalkhoven et al., 1996; King et al., 2001; Page et al., 2002), which functions to activate transcription of many genes involved with inflammatory type reactions and release of cytokines associated with establishment of pregnancy in the pig.

Secretion of interleukin- $1 B$ and oestrogen by the developing porcine conceptuses may function to regulate NF- $\kappa B$ during the establishment of pregnancy in the pig. However, although oestrogen plays a major function in preventing luteolysis and inducing uterine secretions necessary for changes in conceptus morphology for implantation in pigs, the inappropriate timing of uterine exposure to oestrogen (i.e., delivered prior to the normal time of conceptus secretion on day 11 to 12 of gestation) has a detrimental effect on conceptus survival (Pope et al., 1986; Morgan et al., 1987). Premature exposure of the endometrium to oestrogen disrupts the normal expression pattern of uterine and/or conceptus genes during trophoblast attachment, desynchronising the carefully orchestrated temporal and spatial interaction of the uterine environment and conceptuses resulting in early embryonic death. Oestrogen is a major player in controlling NF- $\mathrm{KB}$ activation (Kalaitzidis and Gilmore, 2005) and therefore serves to modulate cytokine release to prevent outbreak of a disease state if $\mathrm{NF}-\kappa \mathrm{B}$ activation is not held in check (Ali and Mann, 2004). It is reasonable to propose that oestrogen serves to modulate unchecked NF- $\kappa B$ activation and therefore prevent inappropriate downstream cytokine release that would lead to an inflammatory "disease" state during implantation.

\section{Role of progesterone in regulation of oestrous cycle and early pregnancy}

Development of a uterine environment that is synchronous with the developing conceptuses is paramount to embryo survival and establishment of pregnancy. Spatiotemporal changes in the uterine luminal environment are controlled by the rapid and sustained increase in plasma progesterone following ovulation in pigs. The role of progesterone in regulating length of the oestrous cycle was demonstrated through its ability to shorten the length of the oestrous cycle following progesterone supplementation shortly after ovulation in cattle (Garrett et al., 1988b) and sheep (Ottobre et al., 1980). In contrast, administration of the antiprogestin, mifepristone, on days 3 to 5 of the sheep oestrous cycle lengthens the oestrous cycle (Morgan et al., 1993). During pregnancy, administration of progesterone prior to the postovulatory period of CL development accelerates conceptus development in cattle (Garrett et al., 1988a) and sheep (Lawson and Cahill, 1983). 
Treatment of gilts with progesterone on days 2 and 3 of pregnancy can advance both uterine secretions and conceptus development (Vallet et al., 1998; Valiet and Christenson, 2004), while treatment with mifepristone slows conceptus development (Vallet and Christenson, 2004). Alteration in length of the oestrous cycle and acceleration of conceptus development during pregnancy following progesterone administration is not as dynamic in the gilt as in the ewe and cow. The more pronounced change in cattle and sheep occurs because concentrations of progesterone in plasma do not increase significantly until days 4 to 5 of the oestrous cycle compared with the rapid increase within $24-36 \mathrm{~h}$ after ovulation in pigs.

\section{Cell-specific expression of progesterone receptors in the uterus}

Progesterone's role in timing both luteolysis during the oestrous cycle and conceptus expansion and implantation during early pregnancy is associated with cell-specific changes in expression of endometrial PR. Sustained stimulation of the uterus by progesterone over 7 to 8 days causes a loss of PR from LE and GE. The ability of progesterone to down-regulate its own receptor within the uterine epithelia is the foundation of the classical McCracken model for luteolysis in sheep (McCracken et al., 1984). There is a clear relationship between loss of PR in LE and GE with luteal regression in cyclic gilts and the onset of rapid conceptus development in pregnant animals. Expression of PR in endometrial LE and GE is down-regulated by day 10 of the oestrous cycle and pregnancy, whereas expression of PR is maintained in stromal cells and myometrium throughout pregnancy (Geisert et al., 1994). Removal of PR from endometrial LE and GE is associated with loss of the large mucin, MUC-1, from the LE apical surface exposing integrins for trophoblast attachment (Bowen et al., 1996). This is also the period when the endometrium releases many cytokines and growth factors to support early development and trophoblast expansion of pig conceptuses on day 12 of pregnancy (see Geisert and Yelich, 1997). Although loss of PR from the uterine epithelium is well established, the mechanism responsible for inhibiting epithelial PR expression during the mid luteal phase (day 10) of the oestrous cycle and early pregnancy is not known. It is clear that down-regulation of epithelial PR precedes the dramatic changes in endometrial secretion and rapid trophoblast expansion and oestrogen secretion by the porcine conceptuses on days 11 to 12 of pregnancy (Geisert and Yelich, 1997).

The processes of implantation in mammals mirror an acute phase inflammatory response as components of the kallikrein-kininogen-kinin system are expressed during implantation in the mouse (Figueroa et al., 2001). There is also pregnancy-specific activation of the kallikrein-kininogen-kinin system in the pig uterus (Vonnahme et al., 1999), including expression of the bradykinin $\beta_{2}$ receptor gene in the pig endometrial LE and GE during the period of conceptus elongation and implantation (Allen et al., 2002). Since kinins induce increased microvascular permeability and vascular growth (Fabre et al., 1999), the kallikrein-kininogen-kinin system likely plays a major role in uterine and placental angiogenesis essential for conceptus survival. A proteoglycan family of acute phase proteins, inter- $\alpha$-trypsin inhibitors (lal), form the LE extracellular matrix (ECM) in the porcine endometrium (Geisert et al., 2003). We propose that the biological role of lal heavy chains is to stabilise the ECM during trophoblast attachment to endometrial LE and release of the serine protease inhibitor, bikunin, which serves as an additional protease inhibitor to prevent conceptus invasion (see Geisert et al., 2004). It is evident that many factors involved with inflammatory type reactions are present during establishment of pregnancy in the pig, which may be triggered through activation of the NF-KB system.

\section{Uterine NF- $K B$ activation}

The NF-KB family of transcription factors regulates tissue immune function, as well as inflammatory and acute phase responses (McKay and Cidlowski, 1998). NF-KB activation targets a 
variety of genes, including those for cell adhesion molecules, cytokines, growth factors and immunoreceptors. NF-kB normally exists as a cytoplasmic heterodimer composed of various Rel family proteins (Ghosh et al., 1998). The heterodimer of $\mathrm{p} 50$ and p65 is the most abundant form of $\mathrm{NF}-\mathrm{KB}$ in eukaryotes. NF- $\mathrm{KB}$ is sequestered in an inactive form within the cytoplasm through binding by inhibitors of NF-KB, IKBs (Ali and Mann, 2004). NF-KB is regulated through receptor activation by variety of stimuli such as bacterial endotoxin lipopolysaccharide, oxidative stress, radiation exposure, and specific cytokines, particularly, interleukin-1ß (IL-1ß) and tumour necrosis factor- $\alpha(T N F \alpha)$. IL-1 1 and TNF $\alpha$ receptor activation stimulates the classical pathway for phosphorylation of two serines in IKB by IKB kinase composed of two catalytic units, IKK $\alpha$ and IKKß and the regulatory subunit IKK $\gamma$. Phosphorylation of IKB results in its release from the NF-KB complex and degradation by polyubiquitination in the $26 \mathrm{~S}$ proteasome (Ghosh et al., 1998). Release of IKB allows nuclear translocation of NF- $\mathrm{kB}$ (p65:p50) for binding to specific $\mathrm{KB}$-sites in the promoter region of target genes to activate transcription. Activation of nuclear $K B$ sites also stimulates $I \times B$ to bind NF-KB and translocate as an inactive complex back to the cytoplasm (negative feedback loop). Endometrial gene expression for p65 and p50 increases between days 5 to 12 in the pig O.W. Ross and R.D. Geisert, unpublished). Genes containing $\mathrm{KB}$ sites that are transcriptionally regulated by NF-KB include many cytokines (TNF $\alpha$, IL-1, IL-2, IL-6, IL-12, LIF and GM-CSF), chemokines (IL-8 and RANTES), and enzymes such as cyclooxgenase-2 (COX-2) (Ali and Mann, 2004). Steroid hormone regulation of uterine receptivity for implantation is modulated through activation of a cascade of events involving many of the NF- $\mathrm{KB}$ regulated adhesion factors, growth factors and cytokines (see Carson et al., 2000; Spencer et al., 2004).

A role for NF-KB activation in regulating uterine function during the oestrous cycle and early pregnancy is emerging in a number of species. Endometrial NF-KB activation is proposed to be involved with implantation in the human (King et al. 2001; Page et al., 2002) and mouse (Nakamura et al., 2004). Endometrial expression of NF-KB proteins is compartmentalised to GE of women (Laird et al., 2000; King et al., 2001) and mice (Nakamura et al., 2004). The porcine endometrium secretes a number of NF-KB regulated cytokines (IL- 6 and LIF) and growth factors such as keratinocyte growth factor (KGF) during the period of rapid conceptus development between days 12 and 15 of pregnancy (see Geisert and Yelich, 1997). There is an 80-fold increase in endometrial COX-2 gene expression from day 5 to day 12 of the oestrous cycle and pregnancy (M.D. Ashworth and R.D. Geisert, unpublished). The increase in endometrial COX-2 gene expression between days 10 and 15 of the oestrous cycle and pregnancy is restricted to uterine LE and GE (Fig. 1) directly after loss of epithelial PR expression (Geisert et al., 1994). The presence of NF-KB in uterine epithelia and the increase in COX-2, the inducible form of cyclooxgenase, in LE and GE indicates a role for NF-KB transcription factors in regulation of uterine functions during the oestrous cycle and pregnancy.

The importance of endometrial NF-KB activation in the establishment of pregnancy is further indicated by conceptus synthesis of a cytokine activator of NF-KB, IL-1ß (Tuo et al., 1996; Ross et al., 2003). IL-1 3 could serve an important function in regulating cross-talk between porcine conceptuses and the endometrium. Our laboratory has established that IL-1 1 is temporally associated with both rapid conceptus elongation and an increase in endometrial IL-1 receptor type I and IL-1 receptor-accessory protein gene expression (Ross et al., 2003). Interestingly, IL-1 receptor type I and II are both molecular markers for uterine receptivity in mice (Reese et al., 2001). Expression of IL-1ß increases prior to initiation of blastocyst implantation in the mouse (Takacs and Kauma, 1996), and it may be an initiator of conceptus-uterine interaction during pregnancy in women (Lindhard et al., 2002). The transient expression of conceptus IL-1ß also suggests an autocrine function to induce the rapid morphological transformation of pig conceptuses from spherical to filamentous forms on day 12 of pregnancy (Geisert et al., 1982). Indeed, porcine conceptus IL-1ß gene expression and release of IL-1ß protein into the uterine lumen is temporally and spatially 
A

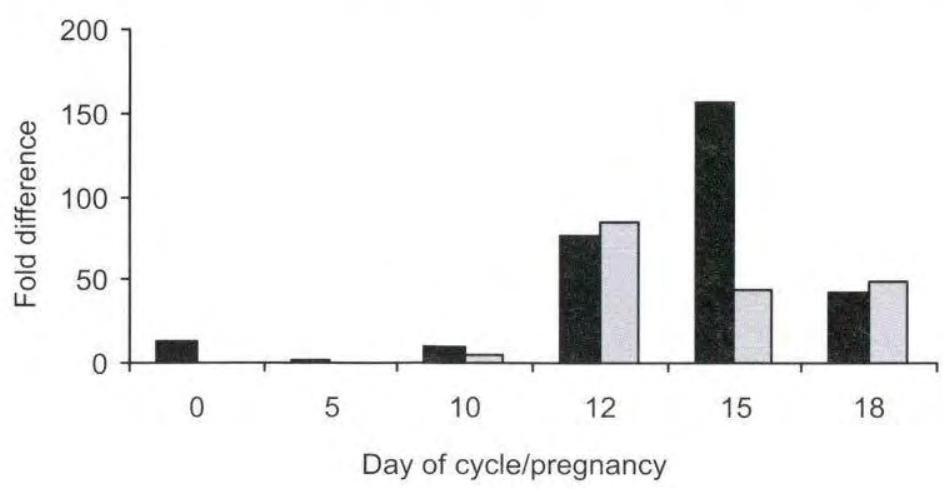

B

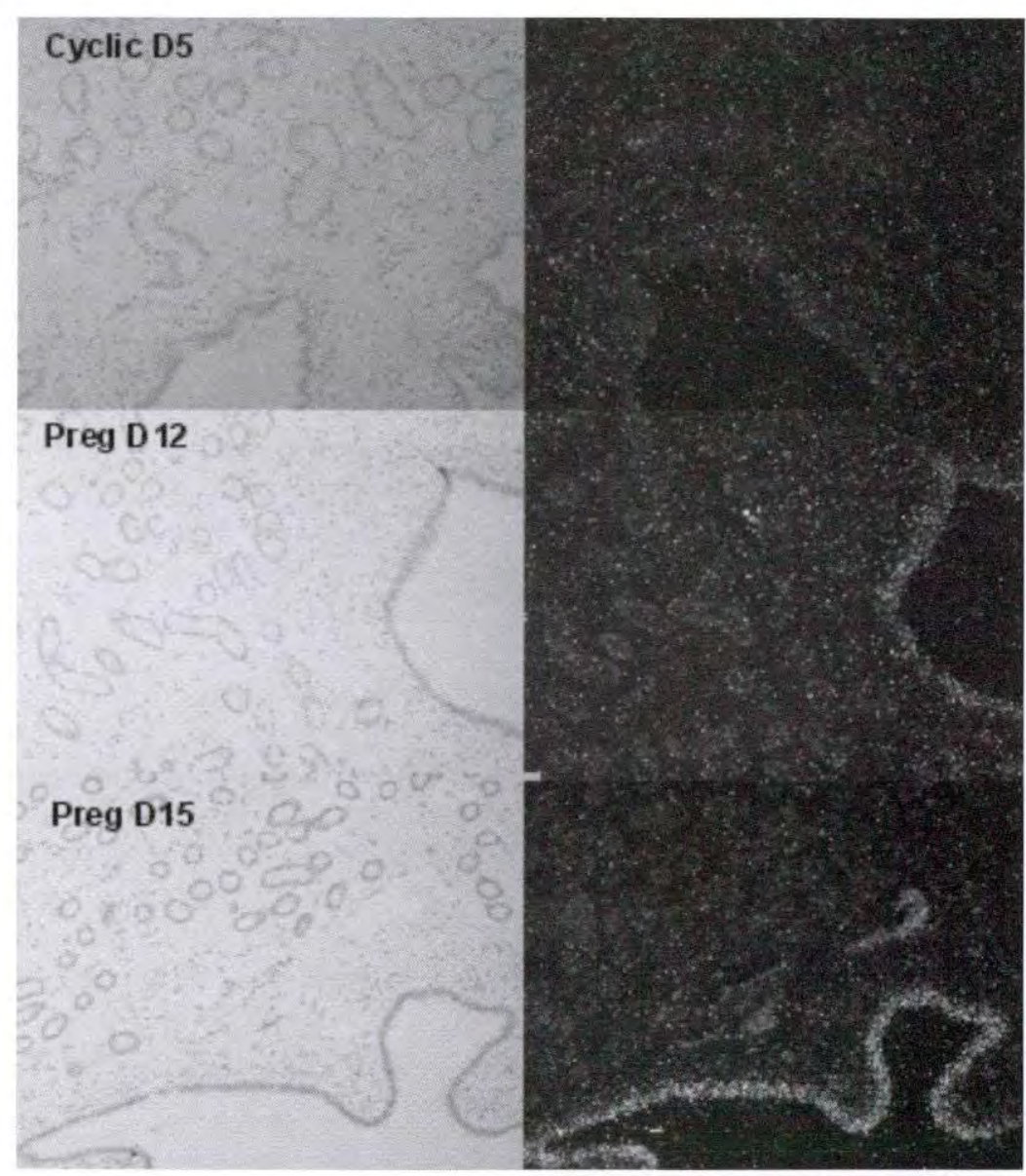

Fig.1 A) Fold change in endometrial COX-2 gene expression during oestrous cycle (black bars); and pregnancy (grey bars). B) In situ hybridisation of endometrial COX-2 gene expression in the luminal and glandular epithelium during the oestrous cycle (day 5) and early pregnancy (days 12 and 15) of the pig. 
associated with rapid trophoblast elongation (Ross et al., 2003). IL-1B, an inducer of phospholipase A2 (Kol et al., 2002), regulates the release of arachidonic acid from the phospholipid bilayer of cells resulting in an increase in membrane fluidity necessary for tissue remodelling during elongation of the conceptus and its conversion to prostaglandins which affect placental attachment during the establishment of pregnancy (Kraeling et al., 1985). Inhibition of NF-KB activation prevents abundant expression of COX-2 gene expression in human trophoblast cells (Kniss et al., 2001). Filamentous (day 12) porcine conceptuses express high levels of COX-2 mRNA (Wilson et

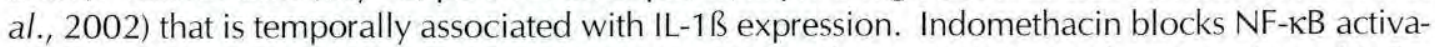
tion of COX-2 expression through inhibition of $I \kappa B \alpha$ kinase activity and suppression of $I \kappa B \alpha$ degradation (Takada et al., 2004). While inhibition of conceptus prostaglandin production with indomethacin does not effect trophoblast elongation (Geisert et al., 1986), prostaglandin synthesis or NF-KB activation is essential for placental attachment and survival following elongation (Kraeling et al., 1985). Implantation in mice and rats require PG synthesis in the oestrogen primed uterus. The importance of endometrial COX-2 gene expression during implantation and decidualisation was established using COX-2 null mice that have an altered inflammatory response resulting in reproductive defects in ovulation, fertilisation and implantation (Lim et al., 1997). These effects are COX-2 specific because COX-1 deficient mice are fertile and only exhibit a defect in parturition (Gross et al., 1998). We hypothesise that IL-1ß signalling is critical to trophoblast elongation (Ross et al., 2003) and induction of endometrial events responsible for cell adhesion and cytokine production associated with establishment and maintenance of pregnancy.

\section{Model for progesterone regulation of uterine $P R$}

Endometrial synthesis and release of $\mathrm{PGF}_{2 \alpha}$ into the uterine vasculature stimulates luteolysis in pigs. Prostaglandin synthesis is regulated through constituent expression of COX-1 and/or the inducible COX-2 (Smith et al., 2000). A slight increase in endometrial COX-1 gene and protein expression occurs after day 12 of both the oestrous cycle and pregnancy (M.D. Ashworth and R.D. Geisert, unpublished); however, during the same period there is a dramatic 80-fold increase in endometrial COX-2 gene expression and a 10-fold increase in COX-2 protein. While increased expression of COX-2 on day 12 of pregnancy is consistent with conceptus secretion of IL-1ß and activation of endometrial NF-KB on day 12 of pregnancy, the increase in COX-2 expression in cyclic females was unexpected. What could induce NF- $\mathrm{kB}$ activity and COX-2 expression within the uterine epithelium on day 10 in the absence of conceptuses? Recent information has revealed an interaction between NF-KB and PR that may explain how the timing of endometrial COX-2 expression on day 10 is under uterine control. Progesterone exerts an inhibitory effect on the synthesis of the proinflammatory chemokine, COX-2, by blocking the NF- $\kappa$ B pathway (McKay and Cidlowski, 1998) and loss of endometrial progesterone stimulation enhances in vivo chemokine release (Jones et al., 1997). Mutual repression between PR and NF-кB activation has been reported and this mechanism could control cytokine release for establishment and maintenance of pregnancy as previously discussed (Kalkhoven et al., 1996; McKay and Cidlowski, 1998). Progesterone has been proposed to inhibit NF-KB activation through its receptor by either directly interfering with NF- $\kappa B$ binding to its consensus DNA response element, inhibiting transcription of ligands and

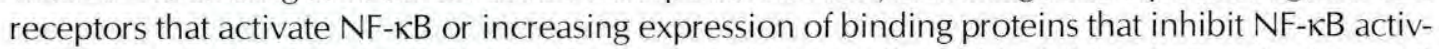
ity (Davies et al., 2004). Therefore, the presence of PR in cells could inhibit NF- $\kappa B$ activation until either: 1) withdrawal of progesterone as would be the case during parturition (Wickelgren, 2004); or 2) PR is down-regulated in progesterone sensitive epithelial cells.

Down-regulation of PR in endometrial epithelia explains loss of endometrial NF- $\mathrm{BB}$ inhibition, but how is this compartmentalised to LE and GE of the uterus while maintaining biologically essential PR expression in the stroma and myometrium throughout pregnancy? One hypothesis for the specificity of PR loss in epithelia is that activation of NF- $\kappa$ B occurs through 
progesterone-stimulated endometrial expression of receptor activator of nuclear factor $\kappa B$ ligand (RANKL). RANKL and its cognate receptor (RANK) have a critical role in bone remodelling and mammary gland development (Holstead-Jones et al., 2002; Cao and Karin, 2003). Deletion of RANKL gene expression causes severe bone osteoporosis and underdeveloped lobuloalveolar buds within the mammary gland (Holstead-jones et al., 2002). In the mammary epithelium, RANKL acts via RANK, which is constitutively expressed to stimulate NF- $\kappa B$ up-regulation of cyclin D1 (see Cao and Karin, 2003). Activation of RANKL expression in mammary epithelium is induced by prolactin and progesterone, but progesterone stimulation may require oestrogen priming (Srivastava et al., 2003). The presence of the prolactin receptor in the porcine endometrium during early pregnancy (Young et al., 1990) indicates that basal concentrations of prolactin could regulate RANKL as proposed in the mammary gland (Srivastava et al., 2003). Mulac-Jericevic et al. (2003) demonstrated that initial activation of RANKL is PR dependent. The pig endometrium expresses RANK during the oestrous cycle and early pregnancy (J.W. Ross and R.D. Geisert, unpublished). Although further studies are needed to establish the cellular localisation and time specific changes in endometrial RANKL and RANK expression, these results support our hypothesis that down-regulation of PR in endometrial LE and GE may be regulated through progesterone and prolactin driven secretion of RANKL (Fig. 2). Constitutive expression of RANK in uterine epithelia would allow RANKL activation of NF-KB leading to epithelial cell specific loss of PR followed by activation of NF-KB stimulated genes such as keratinocyte growth factor (KGF) and COX-2, while PR is maintained in stromal cells and myometrium.

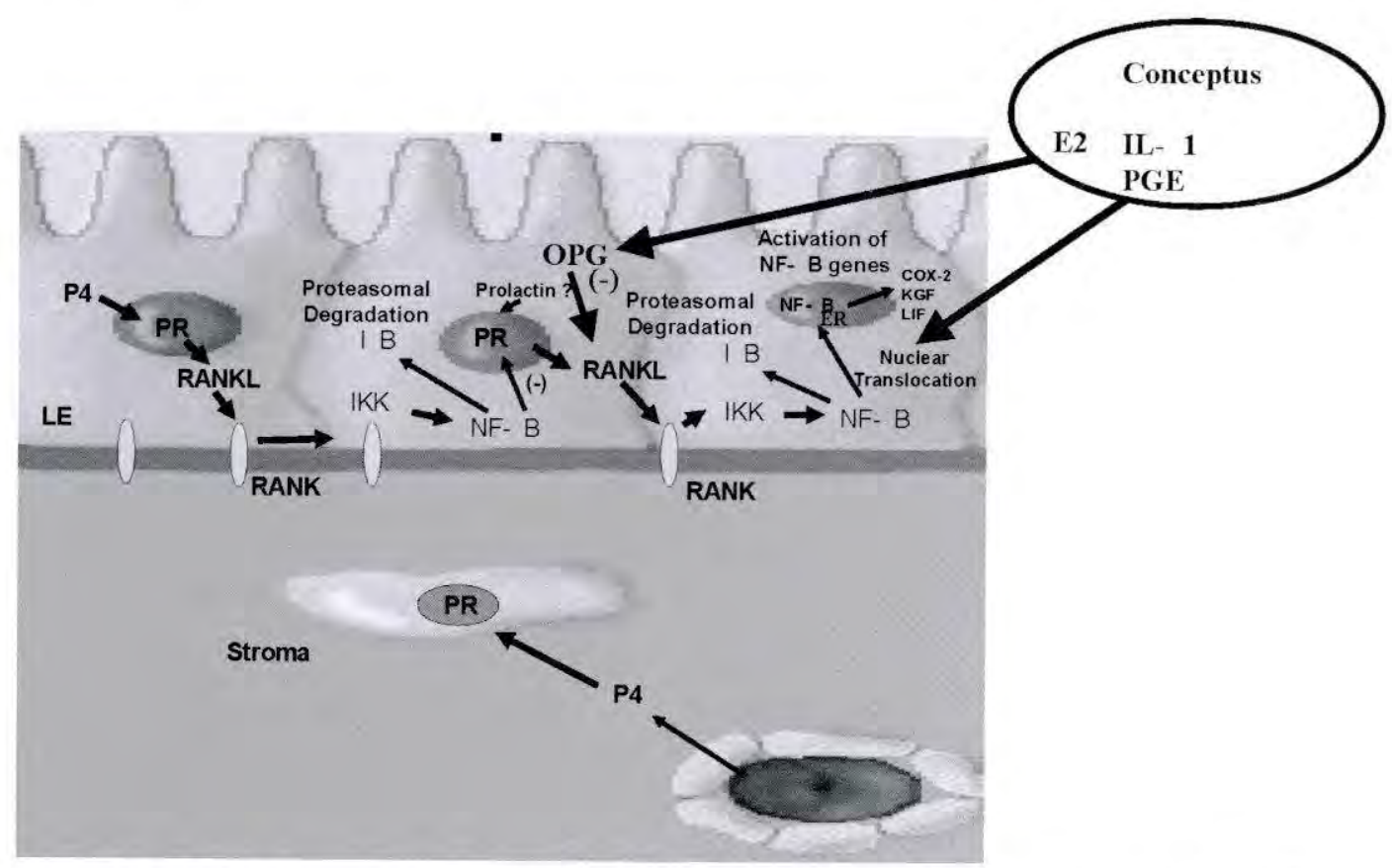

Fig. 2 Model depicting progesterone (P4) stimulation of RANKL expression to induce NFkB activation of PR loss in GE and LE followed by increased expression COX-2, KGF, LIF and OPN at the time of rapid conceptus expansion. Conceptus expression of IL-1B and PGE continues to stimulate NF- $\mathrm{KB}$ activation during early pregnancy. Conceptus oestrogen (E2) secretion modulates NF- $\mathrm{KB}$ gene activation either directly through binding ER within LE and GE or stimulates expression of the decoy receptor osteoprotegerin (OPG) which competes with RANKL for binding to RANK. 
The importance of regulating NF- $\mathrm{KB}$ activation during pregnancy is evident from the large increase in IL-1 1 secretion during rapid trophoblast elongation throughout the uterus on day 12 of pregnancy (Ross et al., 2003). Factors, conceptus or uterine, that activate conceptus IL-1ß synthesis are not currently known. Activation of uterine NF-KB through endometrial RANKL expression could be involved with triggering the acute expression of conceptus IL-1ß. Loss of PR from the endometrial LE and GE, and the increase in endometrial IL-1 receptor type I and IL1 receptor-accessory protein gene expression represent a pathway for cross-talk between conceptus and uterus (Ross et al., 2003). One would predict that the extremely high uterine luminal IL-1 B content during early pregnancy would induce a strong inflammatory response in the uterus. However, only a select set of genes involved with a proinflammatory response are increased, while expression of other NF-KB regulated genes is not detected. A classical inflammatory reaction does not occur and endometrial expression of inflammatory type cytokines, TNF $\alpha$ and IL-1ß, are not increased during the period of implantation (Ross et al., 2003; M.D. Ashworth and R.D. Geisert, unpublished). It is clear that the expression of conceptus IL-1ß decreases acutely following rapid elongation of the conceptuses to prevent development of a chronic endometrial response that would result in rejection of the developing conceptuses. Therefore, conceptuses are likely secrete many factors to control the extent of NF-kB activation during establishment of pregnancy.

Oestrogens secreted by pig conceptuses have been established as the maternal recognition signal that switches secretion of endometrial $\mathrm{PGF}_{2 \alpha}$ from an endocrine to an exocrine direction to prevent $\mathrm{CL}$ regression (Bazer et al., 1982). In addition to a role in CL maintenance, conceptus oestrogens may modulate uterine responses to IL-1 $B$ activation of NF- $\mathrm{kB}$. Conceptus secretion of oestrogens mirrors the increase and decrease of uterine luminal IL-1ß between days 12 and 15 of pregnancy (Ross et al., 2003). Because of the clinical pathology that can emerge if aberrant NF-KB activity occurs in tissues, the anti-inflammatory activity of oestrogens has received increased attention in studies of inflammatory diseases (Kalaitzidis and Gilmore, 2005). Oestrogens regulate tissue gene expression via both oestrogen receptor- $\alpha$ and $-\beta$. Recently, ER $\alpha$ was proposed to suppress NF- $\kappa B$ inflammatory activity through directly inhibiting intracellular transport of p65 to the nucleus (Ghisletti et al., 2005), but this effect could occur at several points in the NF- $\mathrm{KB}$ activation pathway. Expression of ER may inhibit activity of the kinase that phosphorylates $I \kappa B$, inhibit degradation of $I \kappa B$, block DNA binding to the NF- $\kappa B$ dimer or compete for coactivators of NF-KB (see review, Kalaitzidis and Gilmore, 2005). Activation of $\mathrm{NF}-\mathrm{KB}$ in osteoclasts by RANKL can also be inhibited by oestrogen-induction of expression of osteoprotegerin (OPG), which is a soluble TNF receptor family member that competes with RANKL for binding to RANK (Holstead-Jones et al., 2002). The presence of ER $\alpha$ in porcine uterine epithelia (Geisert et al., 1993; Sukjumlong et al., 2004) and ERß in trophoblast (Kowalski et al., 2002) suggests that oestrogen can potentially differentially regulate NF-KB genes through the different ERs expressed in the conceptus and endometrium during the period of conceptus IL-1 $B$ secretion. Increased transcription of NF-KB activated genes may depend upon both the type of ER present and the specific pathway by which NF-KB is activated (Cao and Karin, 2003). Activation of NF-KB is consistent with the increase of KGF expression in porcine uterine LE on day 10 of the oestrous cycle (Ka et al., 2000). Li and Rinehart (1998) demonstrated that IL-1ß stimulates KGF expression in human endometrial fibroblasts through activation of NF-KB while chronic exposure to oestrogen induces a similar response. During pregnancy, expression of KGF in the uterine LE is enhanced at the time of conceptus IL-1ß secretion; however, oestrogen alone can also increase KGF expression in the pig (Ka et al., 2001). Endometrial activation of $\mathrm{NF}-\kappa \mathrm{B}$ provides a unique model to explain epithelial PR down-regulation and expression of 
many cytokines involved with early conceptus development and implantation. Conceptus expression of IL- 1 B would be consistent with continued NF-KB activation with oestrogen providing a modulating role to prevent a full inflammatory reaction that would be detrimental to conceptus survival (Fig. 2).

Secretion of IL-1ß and oestrogen by pig conceptuses may also establish immunological interactions between the endometrium and conceptus during placental attachment. Because pro-IL$1 B$ lacks a signal sequence, its activation and secretion requires cleavage by an intracellular cysteine protease (Fantuzzi and Dinarello, 1999). IL-1ß-converting enzyme (ICE), also known as caspase-1, transforms IL-1ß to its biologically active form. Conceptus expression of ICE occurs coincidentally with IL-1ß secretion on days 12 and 13 of pregnancy (J.W. Ross, M.D. Ashworth and R.D. Geisert, unpublished). Although IL-1ß secretion is minimal on day 15 of pregnancy, there is a second sustained phase of oestrogen secretion by conceptuses that is necessary to maintain CL function beyond 28 days of gestation (Geisert et al., 1987). The second increase of conceptus oestrogen secretion is temporally associated with a pregnancy specific 8-fold increase in endometrial ICE gene expression (M.D. Ashworth, J.W. Ross and R.D. Geisert, unpublished). The increase in endometrial ICE expression is not associated with endometrial release of IL-1ß for which the uterine lumen content is greatly decreased on day 15 and 18 of pregnancy suggesting involvement of an alternate substrate (Ross et al., 2003). Another substrate for ICE, prointerleukin 18 (Pro-IL-18), has structural similarities to Pro-IL-1ß and is involved with modulation of the immune system through induction of interferon- $\gamma$ (Fantuzzi and Dinarello, 1999). Although similar to IL-1ß, IL-18 binds to a unique IL-18 receptor and therefore does not function through the NF- $\mathrm{BB}$ pathway (Lee et al., 2004). IL-18 is expressed by endometrial epithelia (Yoshino et al., 2001) and is suggested to regulate maternal-embryo interplay during establishment of pregnancy. Porcine endometrial IL-18 gene expression increases 4-fold from days 10 to 15 of the oestrous cycle and pregnancy with expression increasing by 10 -fold on day 18 of pregnancy (M.D. Ashworth and R.D. Geisert, unpublished). Although speculative, increased expression of interferon- $\gamma$ following trophoblast elongation and during attachment to the uterine surface from day 15 to 18 of gestation (see review, Cencic and La Bonnardiere, 2002) may be the result of increased endometrial expression of ICE, and possibly the release of IL-18 that induces secretion of interferon- $\gamma$ by conceptuses to modulate the maternal immune system at the interface between trophectoderm and uterine LE (Cencic and La Bonnardiere, 2002).

\section{The role of oestrogen as an endocrine disruptor during early pregnancy}

Although conceptus oestrogens play a major role in preventing luteolysis and inducing uterine changes in secretion and morphology necessary for implantation, the pig endometrium is very sensitive to the timing of oestrogen stimulation. Exposure of the endometrium to oestrogen before the normal period of conceptus secretion on days 11 and 12 of gestation is detrimental to conceptus survival. Consumption of feed containing the oestrogenic mycotoxin, zearalenone, causes total embryonic loss in swine (Long and Diekman, 1986). Pope et al. (1986) first demonstrated that administration of oestrogen to gilts on days 9 and 10 of gestation resulted in complete loss of conceptuses before day 30 of pregnancy; however, no adverse effects occurred when oestrogen was administered on days 12 to 13 (coinciding with endogenous conceptus oestrogen secretion). Our laboratory demonstrated that premature exposure of the pregnant uterus to oestrogen does not effect elongation of conceptuses on day 12, but results in degeneration of conceptuses on day 15 of pregnancy (Morgan et al., 1987). We established that administration of oestrogen on days 9 and 10 of pregnancy is associated with breakdown of 
the apical glycocalyx of endometrial LE which is essential for the heterologous cell-cell interactions necessary for conceptus attachment in the pig (Blair et al., 1991).

The presence of $E R \alpha$ in endometrial LE and GE and the possible role of oestrogen in modulating NF-KB stimulated genes suggests that premature exposure of the uterus to oestrogen may disrupt pregnancy through aberrant gene expression between days 12 and 15 of pregnancy as occurs in mice (Ma et al., 2003). To evaluate this possibility, we utilised a $15 \mathrm{~K}$ unigene porcine cDNA microarray constructed from porcine uterine, ovarian and conceptus tissues (Whitworth et al., 2005), to determine the alterations in endometrial gene expression profiles following treatment of pregnant gilts with oestrogen on days 9 and 10 of pregnancy. Although a number of genes were either up or down regulated on days 10 and 15 of pregnancy, the vast majority of altered endometrial gene expression in response to early oestrogen treatment occurred on day 13 of pregnancy. Many of the differentially expressed genes modified by oestrogen are those known to be involved with cell attachment, immunology, transcriptional regulation and metabolism (Table 1). For example, expression of the osteopontin (OPN) gene was advanced by early oestrogen and this was confirmed in LE by in situ hybridisation (Fig. 3). Osteopontin, a proposed mediator of adhesion of trophectoderm/chorion to endometrial LE through integrin receptors present on the LE apical surface (Johnson et al., 2003), is stimulated by IL-1ß, TNF- $\alpha$, interferon- $\gamma$ and oestrogen. Therefore, alteration in OPN expression may interfere with glycocalyx formation required for conceptus attachment and implantation.

Table 1. Microarray analysis of endometrial genes altered by exogenous oestrogen administration on days 9 and 10 of gestation

\begin{tabular}{|c|c|c|}
\hline & Putative identity & Fold change \\
\hline \multirow[t]{3}{*}{ Day 10} & Retinol-binding protein 4 & 8.2 \\
\hline & Spermidine/spermine N1-acetyltransferase & 6.8 \\
\hline & Integrin, beta 5 & 4.6 \\
\hline \multirow[t]{14}{*}{ Day 13} & Unknown & 9.7 \\
\hline & Unknown & 7.2 \\
\hline & Unknown & 6.0 \\
\hline & F-actin capping protein alpha- 1 subunit & 4.9 \\
\hline & CD24a antigen & 4.5 \\
\hline & Ubiquitin B precursor & 4.4 \\
\hline & Osteopontin & 3.4 \\
\hline & Aldo-keto reductase family 1 & -13.9 \\
\hline & Aldose reductase & -9.6 \\
\hline & Stathmin 1 & -4.5 \\
\hline & Plastin 1 (I isoform) & -4.4 \\
\hline & Programmed cell death 1 ligand 1 & -4.1 \\
\hline & Neuromedin B & -3.7 \\
\hline & Unknown & -3.5 \\
\hline \multirow[t]{2}{*}{ Day 15} & Unknown & 4.3 \\
\hline & Unknown & 3.0 \\
\hline
\end{tabular}

Negative value in fold change indicates gene down-regulated by oestrogen treatment

Early oestrogen administration also altered the pattern of COX-2 expression in endometial LE (Ashworth et al., 2004) suggesting effects on timing of NF- $\mathrm{BB}$ activation. The role of COX-2 expression in LE during establishment of pregnancy has not been investigated; however, it is known that COX-2 null mice have an altered inflammatory response resulting in defects causing implantation failure (Lim et al., 1997). Pharmacological inhibition of PG synthesis through 


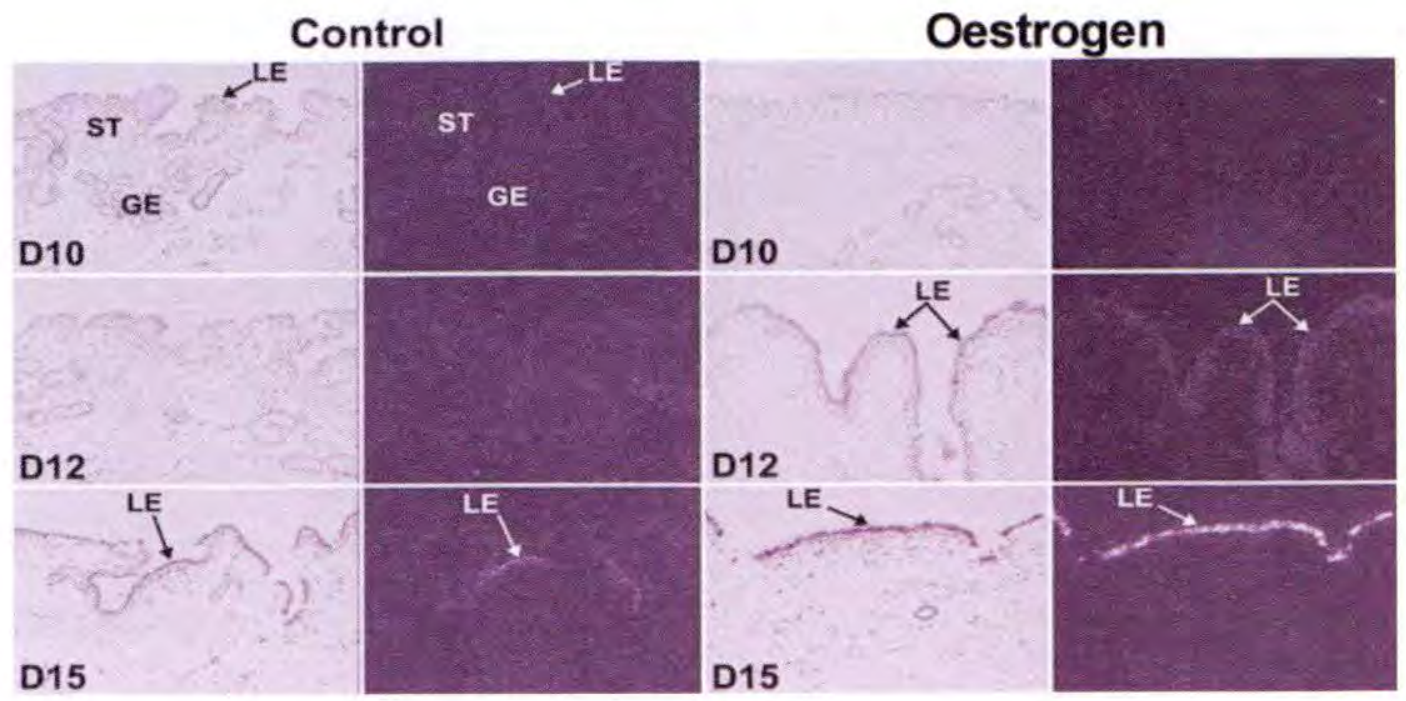

Fig. 3 In situ hybridisation of endometrial osteopontin gene expression in gilts treated with either vehicle (control) or oestrogen on days 9 and 10 of pregnancy. Stroma (ST), Lumeinal Epithelium (LE) and Glandular Epithelium (GE).

inhibition of COX does not affect trophoblast elongation in pigs (Geisert et al., 1986), but it does increase embryonic mortality during the peri-implantation period (Kraeling et al., 1985). Induction of COX-2 expression promotes PGE synthesis (Murakami and Kudo, 2004), and it is known that endometrial secretion of PGE increases during peri-implantation in pigs (see Bazer et al., 1982), perhaps to stabilise the extracellular matrix, inflammation and immune functions.

Treatment of gilts with oestrogen may advance the uterine environment beyond the $24 \mathrm{~h}$ window of synchrony necessary for embryonic survival (Polge, 1982). Indeed early exposure of pregnant gilts to oestrogen disrupts the normal synchrony between the presence of insulinlike growth factors (IGF) in uterine lumen and rapid conceptus elongation on day 12 . Concentrations of IGF-I are elevated within the uterine lumen prior to and during rapid trophoblast expansion on days 10 to 12 of pregnancy in pigs (Simmen et al, 1995; Geisert et al., 2001). Content of IGF-I in uterine flushings decreases dramatically following conceptus elongation and initiation of implantation on day 13 of gestation. The high lumen content of IGF-I is closely associated with the presence of IGF binding proteins (IGFBPs) (Lee et al., 1998; Geisert et al., 2001). Disappearance of uterine luminal IGFBPs on day 11 or 12 of either the oestrous cycle or pregnancy precedes the decline in IGF-I (Geisert et al., 2001). Disappearance of IGFBP's from uterine luminal flushings is caused by an increase in IGFBP proteolysis rather than down-regulation of IGFBP mRNA (Lee et al., 1998). The proteolysis of IGFBPs in the porcine uterine lumen may occur due to activation of serine proteases, tissue kallikrein and/or metalloproteinases (Lee et al., 1998; Geisert et al., 2001). IGF's are regulated and stabilised through tertiary binding to IGFBPs, thus degradation of IGFBP's within the uterine lumen may be responsible for the decreased content of IGF-I in uterine flushings collected after day 13 . It is possible that IGFBPs sequester IGF-I in the uterine lumen for release during the period of conceptus differentiation and trophoblast elongation. The precise timing of the loss of uterine luminal IGFs following conceptus elongation suggests that release of IGFs on days 12 and 13 of pregnancy is critical for subsequent development and survival of pig conceptuses. Administra- 
tion of oestrogen to gilts on days 9 and 10 of pregnancy causes premature proteolysis of uterine luminal IGFBPs on day 10 and an earlier (48 h) decline of IGF-I on days 10 and 11 (M.D. Ashworth and R.D. Geisert, unpublished). Although a causal effect of premature loss of IGFs with later conceptus deaths has not been established, we demonstrated that early oestrogen administration clearly results in a dramatic decline in IGFs before the critical period of conceptus elongation and differentiation. Thus, alterations in the normal synchrony between IGF release into the uterine lumen and conceptus development during early pregnancy may cause aberrant endometrial and/or conceptus gene expression leading to conceptus loss during the peri-implantation period.

\section{Conclusion}

Evidence indicating involvement of the NF- $\mathrm{B}$ B system in regulating endometrial function during the oestrous cycle and early pregnancy has led to the development of a working hypothesis to explain how progesterone regulates the oestrous cycle and early conceptus development in the pig. This working hypothesis is supported by results summarised in this paper and provides the basis for novel approaches for mechanistic studies of uterine PR regulation and oestrogen effects on conceptus survival. Developing an understanding of NF- $\kappa \mathrm{B}$ regulation during early pregnancy and how this transcription factor modulates expression of genes essential for conceptus development and implantation will greatly enhance our ability to improve reproductive efficiencies in swine. Involvement of oestrogen in regulating NF- $\kappa$ B activation provides a clue as to how disruption of NF-KB activation by early oestrogen action on the uterus prevents normal interactions between the conceptus and uterine environment that leads to conceptus death.

\section{Acknowledgements}

Portions of data presented in this review were supported by the National Research Initiative Competitive Grant no. 2002-35203-12262 from the USDA Cooperative State Research, Education, and Extension Service. We would like to acknowledge Drs. Thomas Spencer and Jambo $\mathrm{Hu}$ at Texas A\&M University for contributing the figure for in situ hybridization of endometrial COX-2 expression in the pig and Dr. Fuller Bazer for reviewing our manuscript.

\section{References}

Ali S and Mann DA (2004) Signal transduction via the NF- $\kappa B$ pathway: targeted treatment modality for infection, inflammation and repair Cell Biochemistry and Function 22 67-79

Allen MR, Zhang BR, Hettinger AM, Goad DW, Malayer JR and Geisert RD (2002) Detection of bradykinin and bradykinin- $\$ 2$ receptors in the porcine endometrium during the estrous cycle and early pregnancy Biology of Reproduction 66 574-579

Ashworth MD, Ross JW, Roberts JL, Malayer JR, Day AJ and Geisert RD (2004) Porcine endometrial expression of extracellular matrix components following estrogen disruption of pregnancy Biology of Reproduction Special Issue, p 159 (abstract)
Ashworth MD, Ross JW, Stein DR, Allen DT, Spicer LJ and Geisert RD (2005) Endocrine disruption of uterine insulin-like growth factor (IGF) expression in the pregnant gilt Reproduction 130 545-551

Bazer FW, Geisert RD, Thatcher WW and Roberts RM (1982) The establishment and maintenance of pregnancy. In Control of Pig Reproduction pp 227-252 Eds DJA Cole and GR Foxcroft. Butterworth Scientific, London

Blair RM, Geisert RD, Zavy MT, Short EC, Fulton RW and Yellin T (1991) Endometrial morphological and secretory alterations associated with embryonic mortality in gilts administered estradiol valerate on days 9 and 10 of gestation Biology of Reproduction 44 1063-1079 
Bowen JA, Bazer FW and Burghardt RC (1996) Spatial and temporal analysis of integrin and Muc- 1 expression in porcine uterine epithelium and trophectoderm in vivo Biology of Reproduction 55 1098-1106.

Carson DD, Bagchi I, Dey SK, Enders AC, Fazleabas AT, Lessey BA and Yoshinaga K (2000) Embryo implantation Developmental Biology 223 217-237

Cao $Y$ and Karin $M$ (2003) NF- $\mathrm{KB}$ in mammary gland development and breast cancer fournal of Mammary Cland Biology and Neoplasia 8 215-223

Cencic A and La Bonnardiere C (2002) Trophoblastic interferon-gamma: current knowledge and possible role(s) in early pig pregnancy Veterinary Research 33 139-157

Davies S, Dai D, Feldman I, Pickett $G$ and Leslie KK (2004) Identification of a novel mechanism of NF-KB inactivation by progesterone through progesterone receptors in Hec50co poorly differentiated endometrial cancer cells: induction of A20 and ABIN-2 Gynecologic Oncology 94 463-470

Fabre I, Rivard A, Magner $M$, Silver $M$ and Isner IM (1999) Tissue inhibition of angiotensin-converting enzyme stimulates angiogenesis in vivo Circulation 23 3043-3049

Fantuzzi $C$ and Dinarello CA (1999) Interleukin-18 and interleukin-1B: two cytokine substrates for ICE (caspase-1) Journal of Clinical Immunology 19 1-11

Figueroa CD, Chacon C, Corthorn J, Ehrenfeld P, Muller Esterl $W$ and Valdes $\mathbf{G}$ (2001) Temporospatial changes of kinin $B 2$ receptors during the estrous cycle and pregnancy in the rat uterus Biology of Reproduction 64 1590-1599

Garrett JE, Geisert RD, Zavy MT and Morgan GL (1988a) Evidence for maternal regulation of early conceptus growth and development in the bovine fournal of Reproduction and Fertility 84 437-446

Garrett JE, Geisert RD, Zavy MT, Wettemann RP and Buchanan DS (1988b) Effect of exogenous progesterone on prostaglandin $F_{2 a}$ release and the interestrous interval in bovine. Prostaglandins 36 85.96

Geisert RD and Yelich JV (1997) Regulation of conceptus development and attachment fournal of Reproduction and Fertility Supplement 52 133-149

Geisert, RD, Brookbank JW, Roberts RM and Bazer FW (1982) Establishment of pregnancy in the pig: II. Cellular remodeling of the porcine blastocysts during elongation on day 12 of pregnancy Biology of Reproduction 27 941-955

Geisert, RD, Rasby RJ, Minton JE and Wettemann RP (1986) Role of prostaglandins in preimplantation development of porcine blastocyst Prostaglandins 31 191-204

Geisert RD, Biggers BC, Wettemann RP and Zavy MT (1987) Length of pseudopregnancy and pattern of uterine protein release as influenced by time and duration of oestrogen administration in the pig fournal of Reproduction and Fertility 79 163-172

Geisert RD, Brenner RM, Moffatt JR, Harney JP, Yellin $T$ and Bazer FW (1993) Changes in estrogen receptor protein, mRNA expression and localization in the endometrium of cyclic and pregnant gilts Reproduction, Fertility and Development 5 247-260

Geisert RD, Pratt T, Bazer FW, Mayes IS and Watson GH (1994) Immunocytochemical localization and changes in endometrial progestin receptor protein during the porcine oestrous cycle and early pregnancy Reproduction Fertility and Development 6749 760

Geisert RD, Chamberlain CS, Vonnahme KA, Malayer JR and Spicer L) (2001) Possible role of kallikrein in proteolysis of insulin-like growth factor binding proteins during the oestrous cycle and early pregnancy in pigs Reproduction $121719-728$

Geisert, RD, Ashworth MD and Malayer JR (2003) Endometrial expression of inter- $\alpha$-trypsin inhibitor heavy chains in cyclic and pregnant gilts Reproduction 126 621-627

Geisert RD, Ross JW, Ashworth MD and Malayer JR (2004) Estrogen regulator and/or endocrine disruptor in establishment of pregnancy Current Topics in Steroid Research 4 69-84

Ghisletti S, Meda C, Maggi A and Vegeto E (2005) 17bEstradiol inhibits inflammatory gene expression by controlling NF- $\mathrm{KB}$ intracellular localization Molecular and Cellular Biology 25 2957-2968

Ghosh S, May MJ and Kopp EB (1998) NF-kB and Rel proteins: evolutionarily conserved mediators of immune responses Annual Review of Immunology 16 225-260

Gross GA, Imamura T, Luedke C, Vogt SK, Olson LM, Sadovsky $Y$ and Muglia LJ (1998) Opposing actions of prostaglandins and oxytocin determine the onset of murine labor Proceedings National Academy of Science 95 11875-11879

Holstead Jones D, Kong YY and Penninger JM (2002) Role of RANKL and RANK in bone loss and arthritis Annals of the Rheumatic Diseases 61 ii32-ii39

Ka H, Spencer TE, Johnson GA and Bazer FW (2000) Keratinocyte growth factor: Expression by endometrial epithelia of the porcine uterus Biology of Reproduction $62 \quad 1772.1778$

$\mathrm{Ka} \mathrm{H}$, Jaeger LA, Johnson GA, Spencer TE and Bazer FW (2001) Keratinocyte growth factor is up-regulated by estrogen in the porcine uterine endometrium and functions in trophectoderm cell proliferation and differentiation Endocrinology 142 2303-2310

Kalaitzidis D and Gilmore TD (2005) Transcription factor cross-talk: the estrogen receptor and NF-kB Trends in Endocrinology and Metabolism 16 46-52

Kalkhoven E, Wissink S, van der Saag PT and van der Burg B (1996) Negative interaction between the RelA(p65) subunit of NF- $\mathrm{KB}$ and the progesterone receptor Journal of Biological Chemistry 2716217. 6224

King AE, Critchley HOD and Kelly RW (2001) The NF. $\mathrm{KB}$ pathway in human endometrium and first trimester deciduas Molecular Human Reproduction 7 175183

Kniss DA, Rovin B, Fertel RH and Zimmerman PD (2001) Blockade NF-KB activation prohibits TNF- $\alpha$-induced cyclooygenase-2 gene expression in ED27 trophoblast-like cells Placenta 22 80-89 
Kol S, Kehat 1 and Adashi EY (2002) Ovarian interleukin1 -induced gene expression: privileged genes threshold theory Medical Hypotheses 58 6-8

Kowalski AA, Graddy LG, Vale-Cruz DS, Choi I, Katzenellenbogen BS, Simmen FA and Simmen RC (2002) Molecular cloning of porcine estrogen receptor-beta complementary DNAs and developmental expression in periimplantation embryos Biology of Reproduction 66 760-769

Kraeling RR, Rampacek GB and Fiorello NA (1985) Inhibition of pregnancy with indomethacin in mature gilts and prepuberal gilts induced to ovulate Biology of Reproduction 32 105-110

Johnson CA, Burghardt RC, Bazer FW and Spencer TE (2003) Osteopontin: roles in implantation and placentation Biology of Reproduction 69 1458-1471

Jones RL, Kelly RW and Critchley HO (1997) Chemokine and cyclooxygenase-2 expression in human endometrium coincides with leukocyte accumulation Human Reproduction 12 1300-1306

Laird SM, Tuckerman EM, Cork BA and Li TC (2000) Expression of nuclear factor kappa $B$ in human endometrium; role in control of interleukin 6 and leukaemia inhibiting factor production Molecular Human Reproduction 6 34-40

Lawson RAS and Cahill I.P (1983) Modification of the embryo maternal relationship in ewes by progesterone treatment early in the oestrous cycle journal of Reproduction and Fertility 67 477-483

Lee CY, Green ML, Simmen RCM and Simmen FA (1998) Proteolysis of insulin-like growth factor-binding proteins (IGFBPs) within the pig uterine lumen associated with peri-implantation conceptus development Journal of Reproduction and Fertility $112369-377$

Lee J-K, Kim S-H, Lewis EC, Azam T, Reznikov LL and Dinarello CA (2004) Differences in signaling pathways by $\mathrm{LL}-1 \mathrm{~B}$ and $\mathrm{IL}-18$ Proceedings National Academy of Science $1018815-8820$

Lessey BA, Killam AP, Metzger DA, Haney AF, Greene GL and McCary Jr KS (1988) Immunohistochemical analysis of human uterine estrogen and progesterone receptors throughout the menstrual cycle fournal of Clinical Endocrinology and Metabolism 67334 340

Li Y and Rinehart CA (1998) Regulation of keratinocyte growth factor expression in human endometrium: implications for hormonal carcinogenesis Molecular Carcinogenesis 23 217-225

Lim H, Paria BC, Das SK, Dincuk HE, Langenbach R, Trzaskos JM, Dey SK (1997) Multiple female reproductive failures in cyclooxygenase-2 deficient mice Cell 91 197-208

Lindhard A, Bentin-Ley U, Ravn V, Islin H, Hviid T, Rex S, Bangsboll S and Sorensen S. (2002) Biochemical evaluation of endometrial function at the time of implantation Fertility and Sterility 78 221-233

Long $\mathbf{G}$ and Diekman MA. (1986) Characterization of effects of zeralenone in swine during early pregnancy American Journal of Veterinary Research 47 184-187
Ma W-G, Song H, Das SK, Paria BC and Dey SK (2003) Estrogen is a critical determinant that specifies the duration of the window of uterine receptivity for implantation Proceedings National Academy of Sciences 100 2963-2968

McCracken JA, Schramm W and Okulicz WC (1984) Hormone receptor control of pulsatile secretion of $\mathrm{PGF}_{2 \mathrm{~s}}$ from the ovine uterus during luteolysis and its abrogation in early pregnancy. In Prostaglandins in Animal Reproduction /I pp 31-56 Eds LE Edquist and $\mathrm{H}$ Kindahl. Elvsevier, Amsterdam

McKay LI and Cidlowski JA (1998) Cross-talk between nuclear factor-kappa B and the steroid hormone receptors: mechanisms of mutual antagonism Molecular Endocrinology 12 45-56

Morgan GL, Geisert RD, Zavy MT and Fazleabas AT (1987) Development and survival of porcine blastocysts on day 16 of pregnancy following oestrogen administration on day 9 or days 9 and 10 lournal of Reproduction and Fertility 80 33-41

Morgan GL, Geisert RD, McCann JP, Bazer FW, Ott TL, Mirando MA and Stewart $M$ (1993) Failure of luteolysis and extension of the interoestrous interval in sheep treated with the progesterone antagonist mifepristone (RU 486) Journal of Reproduction and Fertility $98 \quad 451-457$

Mulac-fericevic B, Lydon JP, DeMayo FJ and Conneely OM (2003) Defective mammary gland morphogenesis in mice lacking the progesterone receptor $B$ isoform Proceedings National Academy of Sciences 100 9744-9749

Murakami M and Kudo I (2004) Recent advances in molecular biology and physiology of the prostaglandin $\mathrm{E}_{2}$-biosynthetic pathway Progress in Lipid Research $43 \quad 3-35$

Nakamura H, Kimura T, Ogita K, Koyama S, Tsujie T, Tsutsui T, Shimoya K, Koyama $M$, Kaneda $Y$ and Murata $Y$ (2004) Alteration of the timing of implantation by in vivo gene transfer: delay of implantation by suppression of nuclear factor $\kappa \mathrm{B}$ activity and partial rescue by leukemia inhibitory factor Biochemical and Biophysical Research Communications 321 886-892

Ottobre IS, Lewis GS, Thayne WV and Inskeep EK (1980) Mechanisms by which progesterone shortens the estrous cycle of the ewe Biology of Reproduction 23 1046-1053

Page M, Tuckerman EM, Li TC and Laird SM (2002) Expression of nuclear kappa $B$ components in human endometrium journal of Reproductive Immunology 54 1-13

Polge C (1982) Embryo transplantation and preservation. In Control of Pig Reproduction pp 277-292 Eds DJA Cole and GR Foxcroft. Butterworth Scientific, London

Pope WF, Lawyer MS, Butler WR, Foote RH and First NL (1986) Dose-response shift in the ability of gilts to remain pregnant following exogenous estradiol$17 ß$ exposure lournal of Animal Science 631208 . 1210 
Reese J, Das SK, Paria BC, Lim H, Song H, Matsumoto $H$, Knudtson KL, DuBois RN and Dey SK (2001) Global gene expression analysis to identify molecular markers of uterine receptivity and embryo implantation. Journal of Biological Chemistry 4744137. 44145

Ross JW, Malayer JR, Ritchey JW and Geisert RD (2003) Involvement of the interleukin-1B system in porcine trophoblastic elongation and at the foetal-maternal interface during peri-implantation development $\mathrm{Bi}$ ology of Reproduction 69 1251-1259

Simmen RCM, Green ML and Simmen FA (1995) IGF system in periimplantation uterus and embryonic development. In Molecular and Cellular Aspects of Preiimplantation Processes pp 185-204 Ed. SK Dey. Springer-Verlag, New York

Smith WL, DeWitt DL and Garavito RM (2000) Cyclooxygenases: structural, cellular, and molecular biology Annual Review of Biochemistry 69 145182

Spencer TE and Bazer FW (1995) Temporal and spatial alterations in uterine estrogen receptor and progesterone receptor gene expression during the estrous cycle and early pregnancy in the ewe Biology of Reproduction 53 1527-1545

Spencer TE, Johnson GA, Burghardt RC and Bazer FW (2004) Progesterone and placental hormone actions on the uterus: insights from domestic animals Biology of Reproduction 71 2-10

Srivastava S, Matsuda M, Hou Z, Baily JP, Kitazawa R, Herbst MP and Horseman ND (2003) Receptor activator of NF- $\mathrm{KB}$ ligand induction via Jak2 and Stat5a in mammary epithelial cells The Journal of Biological Chemistry $46 \mathbf{4 6 1 7 1 - 4 6 1 7 8}$

Sukjumlong S, Persson E, Kaeoket K and Dalin A-M (2004) Immunohistochemical studies on oestrogen receptor alpha (ER $\alpha$ ) and the proliferative marker $\mathrm{Ki}-67$ in the sow uterus at oestrus and early pregnany Reproduction of Domestic Animals 39 361-369

Takacs $R$ and Kauma $S$ (1996) The expression of interleukin-1 $\alpha$, interleukin-1ß, and interleukin-1 receptor type I mRNA during preimplantation mouse development Journal of Reproductive Immunology 32 27-35

Takada Y, Bhardwaj A, Potdar P and Aggarwal BB (2004) Nonsteroidal anti-inflammatory agents differ in their ability to suppress NF-kappaB activation, inhibition of expression of cyclooxygenase-2 and cyclin D1, and abrogation of tumor cell proliferation Oncogene 23 9247-9258
Tan J, Paria BC, Dey SK and Das SK (1999) Differential uterine expression of estrogen and progesterone receptors correlates with uterine preparation for implantation and decidualization in the mouse Endocrinology $1405310-5321$

Tou W, Harney JP and Bazer FW (1996) Developmentally regulated expression of interleukin-1B by periimplantation conceptuses in swine Journal of Reproductive Immunology 31 185-198

Vallet IL and Christenson RK (2004) Effect of progesterone, mifepristone, and estrogen treatment during early pregnancy on conceptus development and uterine capacity in swine Biology of Reproduction 70 9298

Vallet IL, Christenson RK, Trout WE and Klemcke HG (1998) Conceptus, progesterone and breed effects on uterine protein secretion in swine fournal of Animal Science 76 2657-2670

Vonnahme KA, Malayer JR, Spivey HO, Ford SP, Clutter AC and Geisert RD (1999) Detection of kallikrein gene expression and enzymatic activity in porcine endometrium during the estrous cycle and early pregnancy Biology of Reproduction 61 1235-1241

Wickelgren I (2004) Premature labor. Resetting pregnancy's clock Science 304 666-668

Wilson ME, Fahrenkrug SC, Smith TPL, Rohrer GA and Ford SP (2002) Differential expression of cyclooxygenase-2 around the time of elongation in the pig conceptus Animal Reproduction Science 71 229-237

Whitworth KM, Agca C, Kim JG, Patel RV, Springer GK, Bivens N, Forrester LJ, Mathialagan N, Green JA and Prather RS (2005) Transcriptional profiling of pig embryogenesis by using a $15 \mathrm{~K}$ member unigene set specific for pig reproductive tissues and embryos Biology of Reproduction 72 1437-1451

Yoshino O, Osuga Y, Koga K, Tsutsumi O, Yano T, Fujii T, Kugu K, Momoeda M, Fujiwara T, Tomita K, Taketani $Y(2001)$ Evidence for the expression of interleukin (IL)-18, IL-18 receptor and IL-18 binding protein in the human endometrium Molecular Human Reproduction 7 649-654

Young KH, Kraeling RR and Bazer FW (1990) Effect of pregnancy and exogenous ovarian steroids on endometrial prolactin receptor ontogeny and uterine secretory response in pigs Biology of Reproduction $43592-599$ 